\title{
Resposta fisiológica de sementes de chia (Salvia hispanica - Lamiales: Lamiaceae) ao estresse salino
}

\author{
Raquel Stefanello * \\ Luiz Augusto Salles das Neves \\ Marisa Aparecida Binotto Abbad \\ Bruna Boucinha Viana \\ Universidade Federal de Santa Maria \\ Avenida Roraima, 1000, Cidade Universitária, CEP 97105-900, Santa Maria - RS, Brasil \\ * Autor para correspondência \\ raquelstefanello@yahoo.com.br
}

Submetido em 10/03/2015

Aceito para publicação em 29/09/2015

\section{Resumo}

O estudo da tolerância à salinidade fornece informações valiosas sobre a propagação da espécie e pode auxiliar tanto na caracterização da cultura, quanto na adequada recomendação para o plantio nestas situações. Assim, objetivou-se com esse trabalho avaliar a resposta fisiológica das sementes de chia ao estresse salino. Para tal, as sementes foram colocadas sobre papel embebido em solução aquosa de cloreto de sódio $(\mathrm{NaCl})$ nos potenciais osmóticos correspondentes a zero; $-0,05 ;-0,10 ;-0,15 ;-0,20 ;-0,25 ;-0,30 \mathrm{MPa}$. Os parâmetros avaliados foram: percentagem de germinação, primeira contagem e índice de velocidade de germinação. Conforme os resultados, a germinação e o vigor das sementes de chia são reduzidos com o aumento da concentração salina. Conclui-se, portanto, que as sementes de chia toleram moderadamente a salinidade nos níveis propostos nesse trabalho, podendo ser intolerantes em potenciais osmóticos inferiores e nas fases iniciais do desenvolvimento de plântulas.

Palavras-chave: Germinação; Salinidade; Vigor

\section{Abstract}

Physiological response of chia seeds (Salvia hispanica - Lamiales: Lamiaceae) to salt stress. The study of salinity tolerance provides valuable information about the propagation of species and can help in both characterizing cultures and in providing correct recommendations for cultivation. The objective of this work was to evaluate the physiological response of chia seeds to salt stress. Seeds were placed on paper in aqueous sodium chloride $(\mathrm{NaCl})$ at osmotic potentials equivalent to zero, $-0.05,-0.10,-0.15,-0.20,-0.25$, and $-0.30 \mathrm{MPa}$. The parameters evaluated were germination percentage, first count, and germination speed index. According to the results, germination and vigor of the chia seeds decrease as salt concentration increases. Therefore, it was concluded that chia seeds are moderately tolerant to salinity levels used in this work and can be intolerant at lower osmotic potentials and in the early stages of seedling development.

Key words: Germination; Salinity; Vigor 


\section{Introdução}

A Salvia hispanica L., popularmente conhecida como chia, é uma planta propagada através de sementes, nativa do sul do México e norte da Guatemala. Essa semente tem sido objeto de investigação, sendo-lhe reconhecidos efeitos benéficos à saúde, devido aos seus elevados teores de proteínas, fibras alimentares, cálcio e ácidos graxos (linolênico - ômega 3), podendo ser considerada uma importante fonte nutricional (SANDOVAL-OLIVEROS; PAREDES-LÓPEZ, 2013).

O fato da chia ser uma excelente fonte de fibra dietética, torna-a um alimento com características benéficas para o metabolismo humano, especialmente no que se refere à sua capacidade de redução do risco de doenças do trato gastrointestinal, de doenças cardiovasculares e dos níveis de colesterol no sangue (COATES, 2012).

As plantas de chia estão sujeitas a condições de estresses que limitam seu crescimento, desenvolvimento e sobrevivência, onde quer que elas cresçam. Em estudos realizados em Salvia aegyptiaca, Gorai et al. (2011) verificaram que essas sementes são sensíveis à salinidade, sendo a germinação inibida em presença do sal ( $\mathrm{NaCl})$. Além disso, Rosa et al. (2015), observaram que as sementes de Salvia splendens apresentaram um limite de tolerância aos sais de $\mathrm{NaCl}$ até aproximadamente $-0,85 \mathrm{MPa}$, sendo que abaixo desse potencial ocorreu a inibição tanto da viabilidade quanto do vigor das sementes.

Em solos com presença de fertilizantes, a concentração de sais pode atingir níveis elevados e, consequentemente, diminuir a germinação das sementes podendo limitar o crescimento e o desenvolvimento das plantas e a produtividade das culturas e, em casos extremos, levar a planta à morte (SANGOI et al., 2009; SOBHANIAN et al., 2011). Entretanto, este comportamento varia com a concentração da solução e com a espécie. Assim, o estudo do efeito do estresse salino em plantas é importante, pois a alta concentração de sais provoca estresse osmótico, o que diminui a absorção de nutrientes, ocasiona distúrbios no metabolismo da planta e, consequentemente, limita a produção agrícola (HARTER et al., 2014).
Dessa forma, a adubação inadequada, as irrigações mal conduzidas e a menor frequência de chuvas devido às mudanças climáticas, sugerem que o desenvolvimento de plantas em condições adversas assume papel importante, evidenciando a capacidade de tais espécies se perpetuarem em ambientes cada vez mais inóspitos (NERY et al., 2009). Assim, considera-se benéfico o conhecimento das espécies capazes de suportar uma determinada condição de estresse salino, tanto para a caracterização da cultura, quanto para auxiliar na adequada recomendação para o plantio nestas situações (REGO et al., 2011).

Portanto, diante do potencial econômico da espécie e da necessidade de informações a respeito do comportamento de suas sementes em ambientes salinos, objetivou-se avaliar a resposta fisiológica das sementes de chia (Salvia hispanica L.) ao estresse salino.

\section{Material e Métodos}

O trabalho experimental foi desenvolvido no Laboratório de Genética Vegetal, do Departamento de Biologia, Centro de Ciências Naturais e Exatas da Universidade Federal de Santa Maria (RS), no período de setembro de 2014 a fevereiro de 2015.

Foram utilizadas sementes de chia (Salvia hispanica L.), família Lamiaceae, adquiridas de uma empresa tradicional em produção e comercialização de sementes, localizada no município de Santa Cruz do

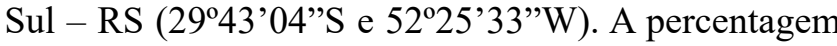
de germinação indicada na embalagem era de $92 \%$.

Para as avaliações do efeito do estresse salino na germinação e no vigor de sementes de chia, utilizou-se solução aquosa de cloreto de sódio $(\mathrm{NaCl})$ nas concentrações correspondentes a zero; $-0,05$; $-0,10 ;-0,15 ;-0,20 ;-0,25 ;-0,30 \mathrm{MPa}$. O nível zero correspondeu à testemunha, onde se utilizou água destilada. A quantidade de $\mathrm{NaCl}$ necessária para obtenção dos potenciais osmóticos foi obtida com base na equação de Van't Hoff citada por Taiz e Zeiger (2013).

O potencial fisiológico das sementes foi avaliado em câmara BOD, com regime de $8 \mathrm{~h}$ de luz e 16 h sem luz, através do teste de germinação realizado em caixas 
plásticas transparentes. As sementes foram depositadas sobre três folhas de papel filtro umedecidas com água destilada no tratamento zero e com as respectivas soluções salinas na proporção de 2,5 vezes o peso do papel (BRASIL, 2009). Após a semeadura, as caixas plásticas foram mantidas na temperatura de $20{ }^{\circ} \mathrm{C}$, sendo a primeira contagem de germinação realizada aos 7 dias e a última contagem aos 14 dias. Avaliou-se a percentagem de germinação e de plântulas anormais (BRASIL, 2009).

Para avaliação do índice de velocidade de germinação (IVG), calculado empregando-se a fórmula de Maguire (1962), as contagens das sementes germinadas foram efetuadas diariamente, no mesmo horário utilizando-se como critério a protrusão da raiz primária.

O delineamento experimental utilizado foi o inteiramente casualizado, onde os tratamentos constituíram-se das diferentes concentrações de $\mathrm{NaCl}$, com quatro repetições de 100 sementes. As variáveis percentagem de germinação, plântulas anormais e primeira contagem foram transformadas em arc sen $\sqrt{x / 100}$. Os dados foram submetidos à análise de variância pelo teste $\mathrm{F}$ e, quando constatado efeito significativo, foi efetuada a análise de regressão pelo programa Sisvar (FERREIRA, 2000).

\section{Resultados}

A análise de variância indicou que as variáveis germinação, plântulas normais, primeira contagem e índice de velocidade de germinação apresentaram diferenças significativas em função dos tratamentos (Tabela 1).
$\mathrm{Na}$ ausência do $\mathrm{NaCl}$ (cloreto de sódio), as sementes apresentaram em média germinação de 88\% (Figura 1), verificando-se uma redução discreta na concentração de $-0,05 \mathrm{MPa}$, chegando a valores inferiores a $50 \%$ no menor potencial osmótico utilizado $(-0,30 \mathrm{MPa})$.

FIGURA 1: Percentagem de germinação de sementes de chia (Salvia hispanica L.) submetidas a diferentes potenciais osmóticos em solução de $\mathrm{NaCl}$.

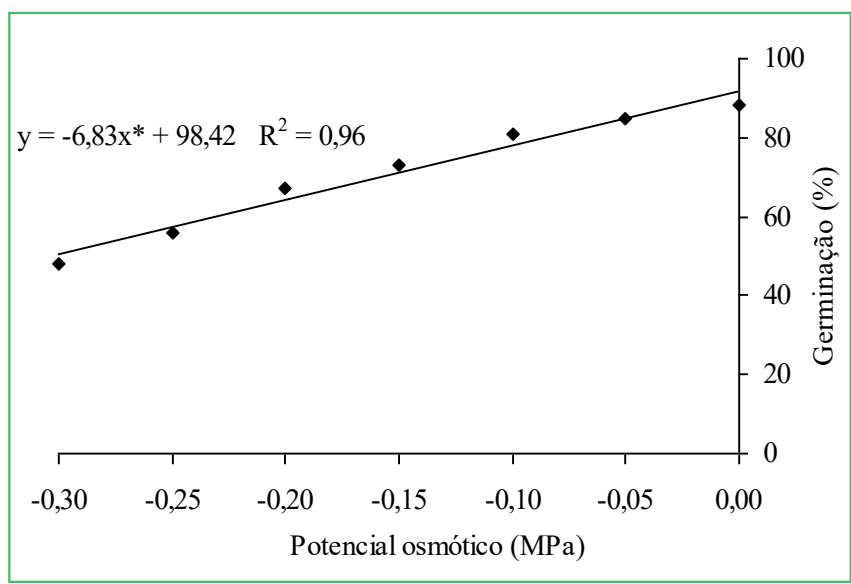

A percentagem de plântulas anormais (Figura 2) foi influenciada pela diminuição do potencial osmótico de $\mathrm{NaCl}$, apresentando em média $4 \%$ de plântulas anormais na concentração zero e atingindo em torno de $40 \%$ no potencial de $-0,30 \mathrm{MPa}$.

$\mathrm{O}$ vigor das sementes avaliado pela primeira contagem de germinação (Figura 3) e pelo índice de velocidade de germinação (Figura 4) foi reduzido com a diminuição do potencial osmótico da solução salina.

TABELA 1: Resumo da análise de variância para as variáveis germinação (G), plântulas anormais (PA), primeira contagem (PC) e índice de velocidade de germinação (IVG) de sementes de chia submetidas a diferentes potenciais osmóticos em solução de $\mathrm{NaCl}$.

\begin{tabular}{lccccc}
\hline \multirow{2}{*}{ Fonte de variação } & Graus de liberdade & \multicolumn{3}{c}{ Quadrado médio } \\
\cline { 3 - 6 } & & $\mathrm{G}$ & $\mathrm{PA}$ & $\mathrm{PC}$ & $\mathrm{IVG}$ \\
Tratamento & 6 & $901,488^{*}$ & $774,904^{*}$ & $2889,321^{*}$ & $544,251^{*}$ \\
Resíduo & 21 & 7,035 & 11,571 & 11,559 & 5,763 \\
CV $(\%)$ & & 3,73 & 16,71 & 7,25 & 3,45 \\
\hline
\end{tabular}

* Significativo a 5\% de probabilidade pelo teste $\mathrm{F}$. $\mathrm{CV}=$ coeficiente de variação. 
FIGURA 2: Percentagem de plântulas anormais de sementes de chia (Salvia hispanica L.) submetidas a diferentes potenciais osmóticos em solução de $\mathrm{NaCl}$.

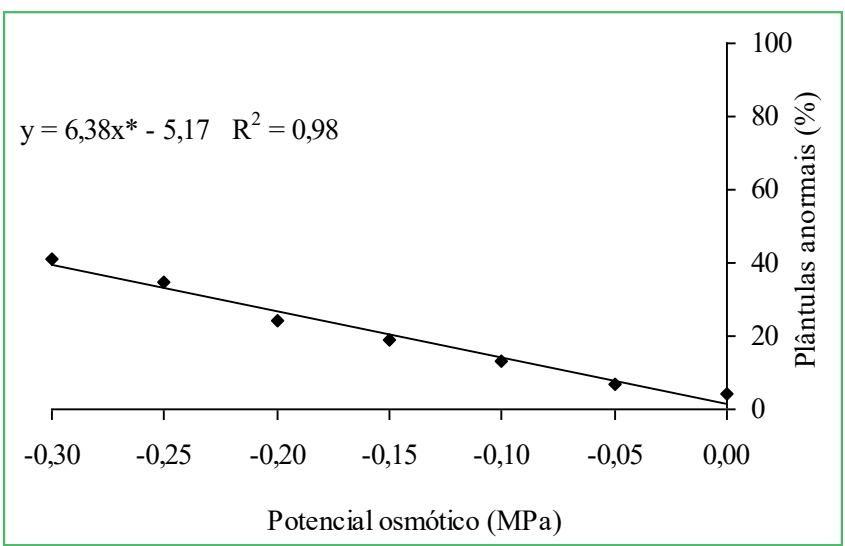

FIGURA 3: Primeira contagem de germinação de sementes de chia (Salvia hispanica L.) submetidas a diferentes potenciais osmóticos em solução de $\mathrm{NaCl}$.

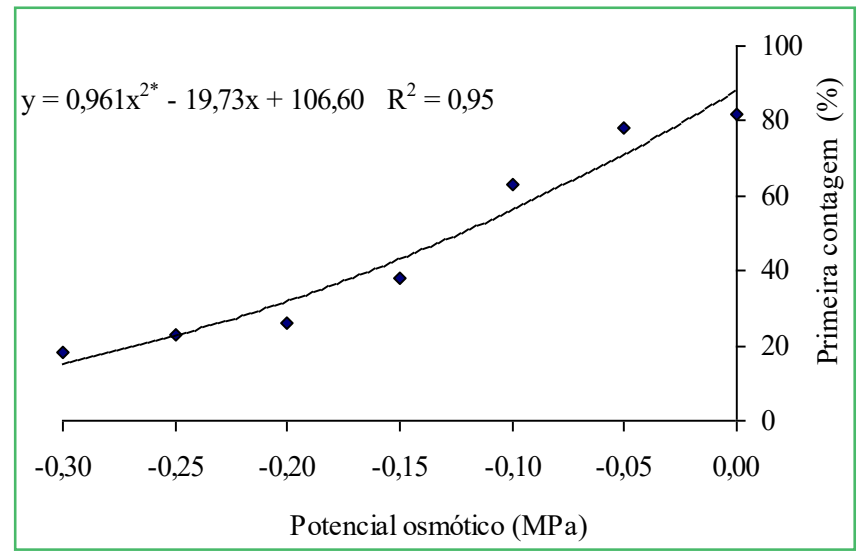

FIGURA 4: Índice de velocidade de germinação (IVG) de sementes de chia (Salvia hispanica L.) submetidas a diferentes potenciais osmóticos em solução de $\mathrm{NaCl}$.

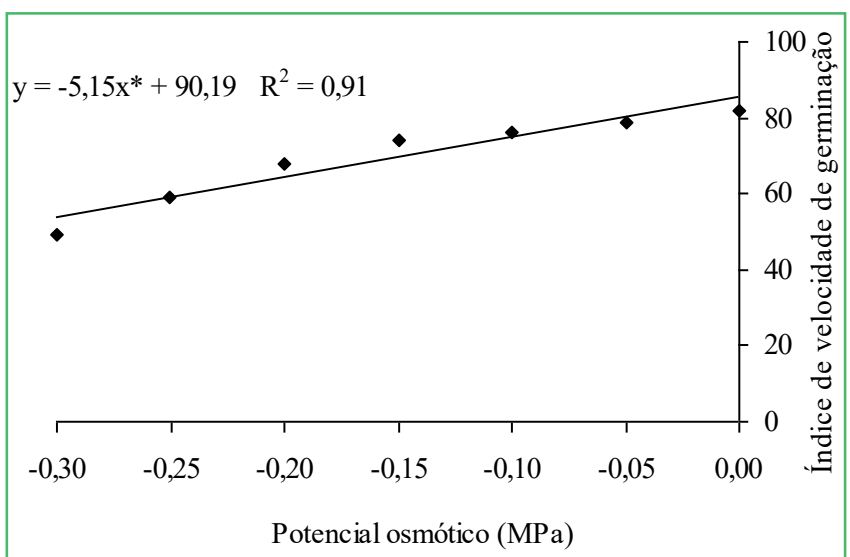

\section{Discussão}

Os resultados deste trabalho corroboram com estudos realizados por Silva et al. (2007) em sementes de cevada (Hordeum vulgare), verificando-se redução na porcentagem de germinação, quando aumentada a concentração de sal, indicando que o cloreto de sódio reduziu a viabilidade das sementes. Também, Gordin et al. (2012), trabalhando com sementes de niger (Guizotia abyssinica), verificaram que a exposição ao $\mathrm{NaCl}$, a partir do potencial osmótico de $-0,30 \mathrm{MPa}$, reduziu o poder germinativo e o crescimento de plântulas.

Por outro lado, em estudos com Salvia splendens, Rosa et al. (2015) observaram que sob os potenciais osmóticos entre $-0,4$ até -2 MPa ocorreu elevada percentagem de plântulas anormais (média de 31,91\%). De acordo com Tobe et al. (2000), os íons $\mathrm{Na}^{+}$e $\mathrm{Cl}^{-}$ são apontados como um dos principais causadores da redução da velocidade dos processos fisiológicos e bioquímicos podendo, mesmo nas condições de baixos potenciais osmóticos, resultar em elevados índices de plântulas anormais.

Verificou-se redução gradativa da velocidade de germinação de acordo com o aumento da concentração de $\mathrm{NaCl}$ no substrato (Figura 4). Da mesma forma, Andréo-Souza et al. (2010) observaram que, em sementes de pinhão-manso (Jatropha curcas), a velocidade de germinação foi o primeiro parâmetro afetado pelo decréscimo da disponibilidade de água, ocasionando maior tempo para a conclusão do processo germinativo. A alta concentração de sais provoca redução do potencial hídrico do solo, resultando em uma menor absorção de água pelas plantas. $\mathrm{O}$ decréscimo deste potencial hídrico, associado ao efeito tóxico dos sais, influencia no processo de absorção de água pelas sementes, o que pode prejudicar a germinação e o desenvolvimento normal das plantas (GHADERI-FAR et al., 2010).

Resultados semelhantes ao desta pesquisa foram obtidos por Gorai et al. (2011), em Salvia aegyptiaca, onde o estresse salino diminuiu a velocidade e a porcentagem da germinação das sementes. Esses mesmos autores concluíram que a Salvia aegyptiaca tem a capacidade de tolerar moderadamente as condições salinas principalmente quando as condições de temperatura se encontram adequadas. Além disso, 
Dal'Maso et al. (2013), analisando a salinidade na germinação e no desenvolvimento inicial das sementes de chia observaram que o aumento da concentração de cloreto de potássio prejudicou a percentagem de germinação, o IVG e o crescimento das plântulas.

Resultados divergentes a este estudo foram obtidos em sementes de fedegoso (Senna obtusifolia), onde a porcentagem e o índice de velocidade de germinação, no potencial de $-0,20 \mathrm{MPa}$, foi maior que o verificado na testemunha (zero), decrescendo com a diminuição deste potencial (PEREIRA et al., 2007). Neste caso, de acordo com Nassif e Perez (1997), o estresse osmótico pode atuar de forma positiva, pois provoca atraso no tempo de germinação das sementes. Como as sementes são heterogêneas na sua resposta ao estresse salino, a germinação é distribuída no tempo, aumentando a probabilidade das plântulas encontrarem condições ambientais adequadas ao seu desenvolvimento.

Por fim, os resultados do teste de germinação e vigor demonstraram que as sementes de chia toleram moderadamente a salinidade nos níveis propostos nesse trabalho na fase de germinação, podendo ser intolerantes em potenciais osmóticos inferiores.

\section{Referências}

ANDRÉO-SOUZA, Y.; PEREIRA, A. L.; SILVA, F. F. S.; RIBEIRO-REIS, R. C.; EVANGELISTA, M. R. V.; CASTRO, R. D.; DANTAS, B. F. Efeito da salinidade na germinação de sementes e no crescimento inicial de mudas de pinhão-manso. Revista Brasileira de Sementes, Londrina, v. 32, n. 2, p. 83-92, 2010.

BRASIL. Ministério da Agricultura, Pecuária e Abastecimento. Regras para análise de sementes. Brasília: Mapa/ACS, 2009. 399 p.

COATES, W. Chia: the complete guide to the ultimate superfood. New York: Sterling Publishing Eds., 2012. 192 p.

DAL'MASO, E. G.; CASARIN, J.; COSTA, P. F.; CAVALHEIRO, D. B.; SANTOS, B. S.; GUIMARÃES, V. F. Salinidade na germinação e desenvolvimento inicial de sementes de chia. Cultivando o saber, Cascavel, v. 6, n. 3, p. 26-39, 2013.

FERREIRA, D. F. Manual do sistema Sisvar para análises estatísticas. Lavras: UFLA, 2000. 69 p.

GHADERI-FAR, F.; GHEREKHLOO, J.; ALIMAGHAM, M. Influence of environmental factors on seed germination and seedling emergence of yellow sweet clover (Melilotus officinalis). Planta Daninha, Viçosa, v. 28, n. 3, p. 436-469, 2010.

GORAI, M.; GASMI, H.; NEFFATI, M. Factors influencing seed germination of medicinal plant Salvia aegyptica L. (Lamiaceae). Saudi Journal of Biological Sciences, Riyadh, v. 18, n. 3, p. 255-260, 2011.
GORDIN, C. R. B.; MARQUES, R. F.; MASETTO, T. E.; SOUZA, L. C. F. Estresse salino na germinação de sementes e desenvolvimento de plântulas de niger (Guizotia abyssinica (L.f.) Cass.). Acta Botanica Brasilica, Belo Horizonte, v. 26, n. 4, p. 966-972, 2012.

HARTER, L. S. H.; HARTER, F. S.; DEUNER, C.; MENEGHELLO, G. E.; VILLELA, F. A. Salinidade e desempenho fisiológico de sementes e plântulas de mogango. Horticultura Brasileira, Brasília, v. 32, n. 1, p. 80-85, 2014.

MAGUIRE, J. D. Speed of germination-aid in selection and evaluation for seedling emergence and vigor. Crop Science, Madison, v. 2, n. 2, p. 176-177, 1962.

NASSIF, S. M. L.; PEREZ, S. C. J. G. A. Germinação de sementes de amendoim do campo (Pterogynes nitens Tul. - FabaceaeCaesalpinoideae) submetidas a diferentes condições de estresse hídrico e salino. Revista Brasileira de Sementes, Londrina, v. 19, n. 2, p. 142-149, 1997.

NERY,A. R.; RODRIGUES, L. N.; SILVA, M. B. R.; FERNANDES, P. D.; CHAVES, L. H. G.; DANTAS NETO, J.; GHEYI, H. R. Crescimento do pinhão-manso irrigado com águas salinas em ambiente protegido. Revista Brasileira de Engenharia Agrícola e Ambiental, Campina Grande, v. 13, n. 5, p. 551-558, 2009.

PEREIRA, M. R. R.; MARTINS, C. C.; MARTINS, D.; SILVA, R. J. N. Estresse hídrico induzido por soluções de PEG e de $\mathrm{NaCl}$ na germinação de sementes de nabiça e fedegoso. Bioscience Journal, Uberlândia, v. 30, n. 3, p. 687-696, 2014.

REGO, S. S.; FERREIRA, M. M.; NOGUEIRA, A. C.; GROSSI, F.; SOUSA, R. K.; BRONDANI, G. E.; ARAUJO, M. A.; SILVA, A. L. L. Estresse hídrico e salino na germinação de sementes de Anadenanthera colubrina (Veloso) Brenan. Journal of Biotechnology and Biodiversity, Gurupi, v. 2, n. 4, p. 37-42, 2011. ROSA, D. C. J.; SOARES, J. S.; MORENO, L. B.; MICHELS, G. M.; C. S. R.; SCALON, S. P. Q.; ROSA, Y. B. C. J. Germinação de Salvia splendens L. submetida à salinidade. Advances in Ornamental Horticulture and Landscaping, Jundiaí, v. 21, n. 1, p. 105-112, 2015.

SANDOVAL-OLIVEROS, M. R.; PAREDES-LÓPES, O. Isolation and characterization of proteins from chia seeds (Salvia hispanica L.). Journal of Agricultural and Food Chemistry, Washington, v. 61, n. 1, p. 193-201, 2013.

SANGOI, L.; ERNANI, P. R.; BIANCHET, P.; VARGAS, V. P.; PICOLI, G. J. Efeitos de doses de cloreto de potássio sobre a germinação e o crescimento inicial do milho, em solos com texturas contrastantes. Revista Brasileira de Milho e Sorgo, Sete Lagoas, v. 8, n. 2, p. 187-197, 2009.

SILVA, R. N.; LOPES, N. F.; MORAES, D. M.; PEREIRA, A. L. A.; DUARTE, G. L. Physiological quality of barley seeds submitted to saline stress. Revista Brasileira de Sementes, Londrina, v. 29, n. 1, p. 40-44, 2007.

SOBHANIAN, H.; AGHAEI, K.; KOMATSU, S. Changes in the plant proteome resulting from salt stress: toward the creation of salt-tolerant crops? Journal of Proteomics, Valencia, v. 74, n. 8, p. 1323-1337, 2011.

TAIZ, L.; ZEIGER, E. Fisiologia vegetal. 5. ed. Porto Alegre: Artimed, 2013. 954 p.

TOBE, K.; LI, X.; OMASA, K. Seed germination and radicle growth of a halophyte, Kalidium capsicum (Chenopodiaceae). Annals of Botany, Oxford, v. 85, p. 391-396, 2000. 